\title{
Fabrikasi Pandu Gelombang Lima Lapis Berbasis Polimer Polystyrene (PS) dan Polymethyl Methacrylate (PMMA)
}

\author{
Faridawati, ${ }^{*}$ Sudarsono, dan Yono Hadi Pramono \\ Jurusan Fisika, Fakultas Matematika dan Ilmu Pengetahuan Alam, \\ Institut Teknologi Sepuluh Nopember (ITS), Kampus ITS Sukolilo, Surabaya 60111
}

Intisari

\begin{abstract}
Telah dilakukan penelitian untuk memfabrikasi pandu gelombang slab lima lapis berbasis bahan polimer polystyrene (PS) 3\%, dan polymethyl methacrylate (PMMA) 2\%, dengan menggunakan metode spin coating. Komposisi pandu gelombang lima lapis yang dibuat terdiri dari bahan PS sebagai film dengan indeks bias bahan 1,59 dan bahan PMMA sebagai kover dan gap (pemisah) dengan indeks bias 1,49. Berdasarkan hasil fabrikasi didapatkan ketebalan $7,4 \mu \mathrm{m}$ untuk PS sebagai film dan $10,93 \mu \mathrm{m}$ untuk PMMA sebagai kover serta $4,84 \mu \mathrm{m}$ untuk PMMA sebagai pembatas. Dua pandu gelombang tersebut dapat digunakan sebagai directional coupler.
\end{abstract}

\begin{abstract}
Fabrication of five-layer waveguides with slab structur based on polymer materials polystyrene (PS) $3 \%$ and polymethyl methacrylate (PMMA) 2\% using the spin coating method has been carried out. The composition of five-layer waveguides were polystyrene as film with a refractive index 1.59 and PMMA as cover and gap with refractive index of 1.49. Based on the results obtained thickness $7.4 \mu \mathrm{m}$ fabrication for polystyrene film and $10.93 \mu \mathrm{m}$ for PMMA as a cover and $4.84 \mu \mathrm{m}$ for PMMA as a gap. Two waveguides are expected to be used as a directional coupler.
\end{abstract}

KATA KUNCI: waveguides, polystyrene, PMMA, spin coating, directional coupler

\section{PENDAHULUAN}

Fabrikasi dan karakterisasi pandu gelombang optik berbahan polymer telah banyak dilakukan, dikarenakan kemudahan dalam pembentukannya dan biaya produksi yang relatif murah [1-4]. Penggunaan polimer sebagai bahan pandu gelombang mempunyai beberapa keunggulan antara lain: proses fabrikasi relatif mudah dan dapat dicetak pada suhu rendah, sifat bias rangkap rendah, dan kekuatan mekaniknya bagus [5, 6].

Beberapa bahan polimer yang lazim digunakan sebagai pandu gelombang optik berstruktur slab diantaranya polystyrene (PS) dan polymethyl methacrylate (PMMA). Pandu gelombang optik slab dapat difabrikasi dengan beberapa metode, salah satunya adalah metode spin coating. Metode ini dilakukan dengan meneteskan suatu larutan pada sebuah substrat, kemudian memutarnya dengan kecepatan tertentu.

Pada paper ini dilaporkan hasil fabrikasi pandu gelombang optik struktur slab lima lapis dengan menggunakan metode spin coating, dengan hasil sesuai yang diharapkan sebagai syarat pandu gelombang moda tunggal, dengan tebal lapisan kedua dan keempat yang bertindak sebagai film memiliki ketebalan yang lebih tipis bila dibandingkan dengan lapisan

\footnotetext{
*E-MAIL: Faridawati.farida80@gmail.com
}

pertama dan lapisan kelima yang bertindak sebagai kover. Lapisan ketiga yang bertindak sebagai gap dibuat setipis mungkin agar ketika pandu gelombang difungsikan bisa terjadi kopling.

\section{METODOLOGI}

Pada penelitian ini telah dilakukan fabrikasi pandu gelombang slab lima lapis dengan substrat kaca dan susunan lapisan PMMA-PS-PMMA-PS-PMMA dengan menggunakan metode spin coating. Metode spin coating merupakan metode yang cukup mudah namun sudah mampu menghasilkan lapisan yang baik. Susunan pandu gelombang lima lapis yang difabrikasi diharapkan menjadi dua pandu gelombang simetri dengan PS sebagai film sedangkan PMMA sebagai kover dan gap. Karakterisasi pandu gelombang diamati dengan menggunakan mikroskop dan pemanduan berkas cahaya laser He-Ne.

\section{Spin coating}

Spin coating adalah suatu prosedur yang digunakan untuk membuat lapisan yang dilapiskan ke permukaan substrat, dengan cara meneteskan atau menyemprotkan sedikit larutan untuk lapisan ke atas substrat, kemudian substrat diletakkan pada 


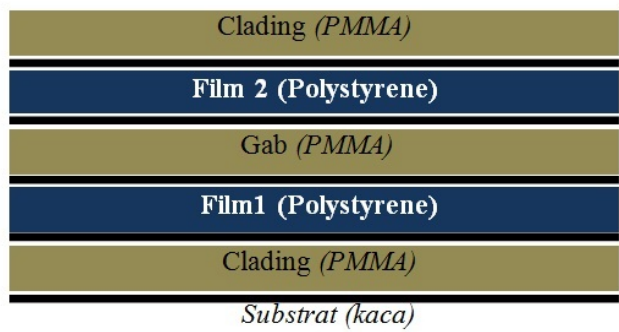

Gambar 1: Struktur pandu gelombang lima lapis.

alat pemutar dan diputar dengan kecepatan tinggi serta konstan, sehingga larutan akan menyebar dan dapat diperoleh endapan film di atas substrat. Semakin cepat putaran, akan diperoleh film yang semakin tipis. Metode ini sangat mudah dan efektif untuk membuat lapisan dengan variasi ketebalan hanya dengan mengatur parameter waktu, kecepatan dan viskositas serta densitas dari larutan.

\begin{abstract}
Alat dan bahan
Bahan yang digunakan adalah kaca preparat sebagai substrat, serbuk PS dan larutan PMMA sebagai bahan pembuat lapisan serta sabun tepol dan alkohol untuk membersihkan substrat dari kotoran yang menempel pada permukaan. Peralatan yang digunakan diantaranya ampelas untuk meratakan tepi substrat, seperangkat alat spin coater yang digunakan untuk proses pelapisan, magnetic stirrer yang digunakan untuk membuat larutan PS-toluen, hot plate untuk pemanasan hasil fabrikasi lapisan, mikroskop yang digunakan untuk pengamatan dan menentukan ketebalan lapisan serta laser He-Ne sebagai sumber cahaya. Preparasi substrat dilakukan dengan memotong kaca preparat dengan ukuran panjang $2 \mathrm{~cm}$ dan lebar $1 \mathrm{~cm}$. Langkah awal setelah substrat dipotong terlebih dahulu permukaan samping substrat diratakan dengan amplas ukuran 240, 360, 500, 800, 1500 dan 2000, kemudian substrat dibersihkan, dicuci menggunakan aceton lalu dikeringkan menggunakan hair dryer. Proses ini dilakukan berulang-ulang sampai dipastikan bahwa substrat benar-benar bersih.
\end{abstract}

\section{Fabrikasi lapisan}

Pembuatan larutan PS 3\% dilakukan dengan melarutkan bubuk PS pada pelarut toluene. Pencampuran larutan dilakukan dengan cara pengadukan dengan menggunakan magnetik stirrer selama 5-6 jam sampai didapatkan larutan homogen. Setelah pembuatan larutan berhasil langkah selanjutnya adalah pembuatan lapisan dengan menggunakan alat spin coating.

Lapisan pertama yang dibuat yaitu PMMA, menggunakan alat spin coater dengan kecepatan 2000 rpm selama 60 sekon. Selanjutnya lapisan yang terbentuk dipanaskan pada temperatur $80^{\circ} \mathrm{C}$ selama 1 menit dan didiamkan semalam untuk kembali dilapisi pada hari berikutnya. Setelah didiamkan selama satu hari tahap berikutnya adalah pelapisan kedua PS

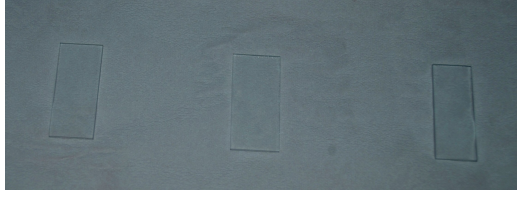

(a)

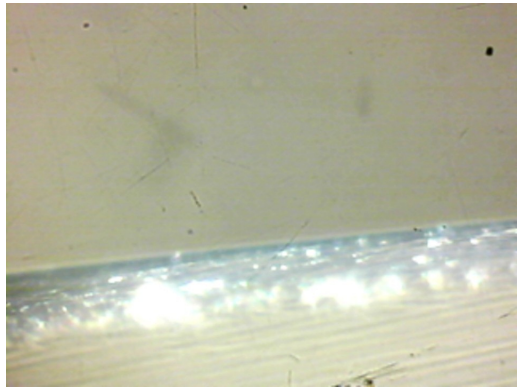

(b)

Gambar 2: Substrat kaca, (a).permukaan (b). penampang melintang.

dengan kecepatan $2500 \mathrm{rpm}$ selama 60 sekon, selanjutnya lapisan dipanaskan pada temperatur $80^{\circ} \mathrm{C}$ selama 1 menit dan didiamkan sehari semalam untuk dilapisi kembali pada hari berikutnya. Langkah yang sama diulang untuk lapisan ke tiga, lapisan ke empat dan lapisan ke lima. Variasi kecepatan rotasi masing-masing $3000 \mathrm{rpm}, 2500 \mathrm{rpm}$, and $2000 \mathrm{rpm}$. Struktur pandu gelombang lima lapis yang di fabrikasi ditunjukkan pada Gambar 1.

\section{Karakterisasi lapisan}

Untuk mengetahui lima lapis lapisan yang telah terbentuk, maka masing-masing hasil proses pelapisan diamati dengan menggunakan mikroskop yang telah dilengkapi dengan kamera webcam. Sampel disinari dengan cahaya polikromatik pada sisi yang dilapisi. (dalam penelitian ini menggunakan lampu halogen). Mikroskop difokuskan sampai ketebalan lapisan terlihat. Setelah fokus kemudian hasilnya di foto dengan webcam dan disimpan dalam bentuk file (*.jpg).

\section{HASIL DAN PEMBAHASAN}

Gambar 2(a) menunjukkan substrat kaca dengan ukuran 1 $\times 2 \mathrm{~cm}$ yang tepinya telah digosok dengan amplas dan dicuci menggunakan sabun serta dibilas dengan alkohol. Sedangkan Gambar 2(b) merupakan hasil pengamatan substrat kaca sebelum dilapisi dengan menggunakan mikroskop.

Setelah substrat kaca cukup bersih, maka dilakukan pelapisan dengan menggunakan menggunakan alat spin coating, dengan struktur lapisan dan komposisi mengacu pada Gambar 1. Lapisan pertama berupa PMMA, lapisan kedua PS, lapisan ketiga PMMA, lapisan keempat PS, dan lapisan kelima PMMA. Hasil fabrikasi untuk masing-masing pelapisan dari lapisan satu sampai lima seperti ditunjukkan pada Gambar 3 . 


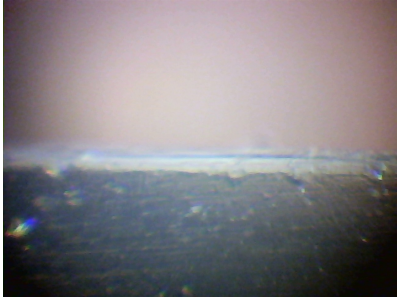

(a) Satu lapis

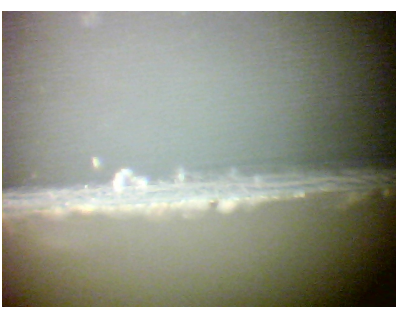

(c) Tiga lapis

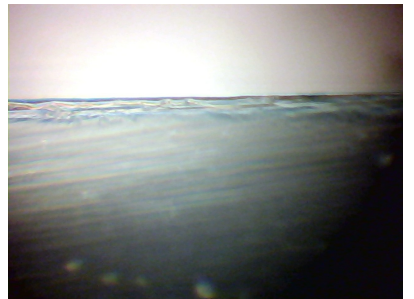

(b) Dua lapis

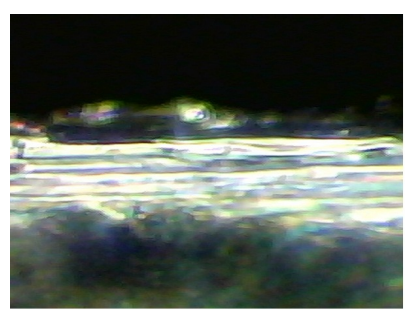

(d) Empat lapis

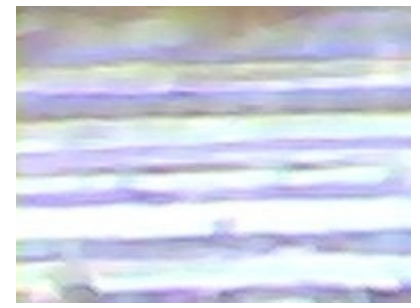

(e) Lima lapis

Gambar 3: Hasil fabrikasi pandu gelombang lima lapis.

Setelah proses pembuatan lima lapisan telah selesai dilakukan, maka selanjutnya dilakukan pengukuran ketebalan lapisan. Pengukuran ketebalan dilakukan dengan cara membuat perbandingan skala pixel dengan skala mikrometer. Penentuan skala pixel adalah dengan menggunakan persamaan:

$$
1 \text { pixel }=\frac{\text { pergeseran }}{\text { pixel }_{1}-\text { pixel }_{2}}
$$

dengan "pergeseran" menyatakan besarnya pergeseran pada mikrometer, pixel $_{1}$ adalah posisi gambar sebelum digeser, pixel $_{2}$ adalah posisi gambar setelah digeser. Contoh perhitungan jarak antar pixel ditunjukkan Gambar 4 dengan data ditunjukkan Tabel I, dengan rata-rata jarak 1 pixel adalah 0,169 $\mu \mathrm{m}$, yang digunakan untuk mengukur ketebalan lapisan film dengan persamaan:

$$
\text { Tebal lapisan }(\mu \mathrm{m})=\Delta \text { pixel } \times 0,169
$$

Ketebalan lapisan sampel hasil fabrikasi ditunjukkan pada Tabel II.

Pada Tabel I hasil pengukuran pergeseran pixel, pengukuran jarak antar pixel perlu dilakukan terlebih dahulu sebelum mengukur ketebalan lapisan, hal ini dilakukan untuk mempermudah penentuan ketebalan lapisan. Jarak yang didapatkan dari gambar berupa jarak antar pixel sehingga perlu dilakukan konversi antara pergeseran mikrometer dengan pergeseran pixel pada gambar. Pada pengukuran jarak antar pixel dilakukan dengan cara menggeser $10 \mu \mathrm{m}$ sebanyak lima kali

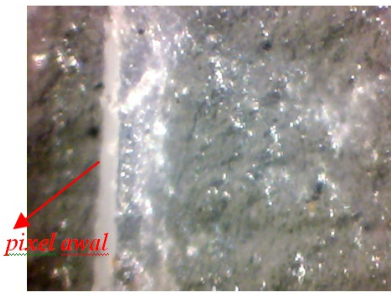

(a) Sebelum digeser

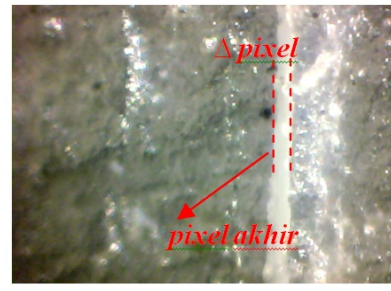

(b) Setelah digeser
Gambar 4: Contoh foto untuk kalibrasi skala.

TABEL I: Hasil perhitungan jarak 1 pixel.

\begin{tabular}{ccccc}
\hline \hline $\begin{array}{c}\text { No Pergeseran Pixel Pixel Jarak 1 pixel } \\
(\mathrm{mm})\end{array}$ & awal & akhir & $(\mathrm{mm})$ \\
\hline & & & & \\
1 & 0,01 & 254 & 314 & 0,000167 \\
2 & 0,01 & 314 & 370 & 0,000178 \\
3 & 0,01 & 370 & 424 & 0,000185 \\
4 & 0,01 & 424 & 486 & 0,000161 \\
5 & 0.01 & 486 & 552 & 0.000152 \\
\hline \hline
\end{tabular}

pada skala mikrometer yang menempel pada dudukan sampel. Hasil pergeseran pixel terlihat pada Tabel I sehingga didapatkan jarak 1 pixelnya adalah $0,169 \mu \mathrm{m}$. Hasil inilah yang dipakai untuk mengukur ketebalan masing-masing lapisan.

Pada Tabel II menunjukkan hasil pengukuran ketebalan lapisan menggunakan mikroskop dengan perbesaran 150 kali. Dari hasil pengukuran tersebut terlihat bahwa dalam satu sampel lapisan pertama dan kelima mempunyai ketebalan paling tebal dibandingkan dengan lapisan kedua, ketiga dan keempat. Hal ini sudah sesuai dengan yang diharapkan karena lapisan pertama dan kelima digunakan sebagai kover. Sedangkan lapisan kedua dan keempat lebih tipis dibandingkan dengan yang pertama dan kelima hal ini bertujuan lapisan kedua dan keempat digunakan sebagai film, sehingga diupayakan terbentuk lapisan setipis mungkin agar terbentu pandu gelombang moda tunggal. Lapisan ketiga mempunyai ketebalan paling kecil dibandingkan dengan keempat lapisan yang lain, hal ini dilakukan karena lapisan ketiga digunakan sebagai gap. Gap dibuat sekecil mungkin agar ketika pandu gelombang tersebut ketika difungsikan sebagai directional coupler dapat dengan mudah terjadi kopling. Pada proses pelapisan untuk bahan dan kecepatan putar lapisan pertama sama dengan lapisan kelima, sedangkan lapisan kedua sama dengan lapisan keempat sehingga akan menghasilkan ketebalan yang

\begin{tabular}{|c|c|c|c|c|c|}
\hline No & \multicolumn{2}{|c|}{ Ketebalan } & \multicolumn{3}{|c|}{ L a p i s a n $(\mu \mathrm{m})$} \\
\hline Sampel & 1 (PMMA) & $2(\mathrm{PS})$ & 3 (PMMA) & 4 (PS) & 5 (PMMA) \\
\hline 1 & 10,836 & 9,030 & 6,622 & 10,234 & 12,040 \\
\hline 2 & 11,438 & 9,632 & 7,224 & 9,632 & 12,041 \\
\hline 3 & 13,244 & 10,234 & 7,826 & 8,428 & 14,448 \\
\hline 4 & 12,040 & 8,428 & 6,020 & 9,632 & 13,244 \\
\hline
\end{tabular}

TABEL II: Hasil pengukuran ketebalan lapisan. 
sama pula pada lapisan pertama dengan kelima dan lapisan kedua dengan lapisan keempat. Namun dari hasil pengukuran terdapat perbedaan antara lapisan-lapisan tersebut, hal ini dapat disebabkan karena pengaturan waktu secara manual sehingga meskipun kecil akan tetap memberikan perbedaan lama waktu putar pada masing-masing lapisan sehingga memberikan ketebalan yang berbeda. Sedangkan untuk bahanbahan yang digunakan dipilih bahan PS sebagai lapisan kedua dan keempat karena lapisan kedua dan keempat sebagai film, sehingga harus mempunyai indeks bias lebih besar dibandingkan dengan indeks bias kover dan gap. Polysterene mempunyai indeks bias 1,59 sedangkan PMMA 1,49 sehingga memenuhi syarat untuk menjadi pandu gelombang. Prinsip dasar dari pandu gelombang optik adalah terjadinya pemantulan dalam total dan hal tersebut dapat terjadi jika indeks bias film lebih besar dari pada indeks bias kover atau substrat. Pada penelitian ini hanya dilakukan fabrikasi pandu gelombang optik struktur slab lima lapis, yang kedepannya pandu gelombang tersebut diharapkan dapat difungsikan sebagai dua pandu gelombang optik yang simetri sehingga juga dapat difungsikan sebagai directional coupler.

\section{SIMPULAN}

Telah berhasil difabriasi pandu gelombang slab lima lapis dengan susunan lapisan PMMA-PS-PMMA-PS-PMMA dengan metode spin coating. Lapisan paling tipis terdapat pada lapisan ketiga dengan ketebalan $6,02 \mu \mathrm{m}$ dan lapisan paling tebal terdapat pada lapisan kelima dengan ketebalan 14,448 $\mu \mathrm{m}$. Pengukuran ketebalan dapat dilakukan menggunakan mikroskop dengan perbesaran 150 kali dengan menentukan besar jarak antar pixel yang berdekatan. Pada penelitian ini didapatkan jarak satu pixel adalah 0,169 $\mu \mathrm{m}$.
[1] F. Qiu, et al., Eur. Polym. J., 49, 2247-2256 (2013).

[2] M. Rezem, et al., Proc. Tecnol, 15, 514-512 (2014).

[3] Y. Gao, et al., Optics Communications, 285, 5107-5112 (2012).

[4] Y. Binfeng, et al., Optics Communications, 354, 83-89 (2015).
[5] A.F. Gavela, M.G. Granda, J.R. Garcia, Optical materials, 47, 83-87 (2015).

[6] M.E. Camilo, et al., Thin Solid Film, 571, 225-229 (2014). 